\title{
Accessing the southeastern Brazil 2014 drought severity on the vegetation health by satellite image
}

\author{
Ana Carolina Campos Gomes ${ }^{1} \cdot$ Nariane Bernardo $^{1} \cdot$ \\ Enner Alcântara ${ }^{2}$ (iD
}

Received: 27 May 2017/Accepted: 19 August 2017/Published online: 30 August 2017

(C) Springer Science+Business Media B.V. 2017

\begin{abstract}
Droughts are natural events that can cause water scarcity and can consequently have undesired environmental, social and political effects. Because droughts are related to land use and land cover modifications, satellite images are used to monitor and identify drought episodes through indices as Standardized Precipitation Index based on rainfall data and vegetation-based indices as Normalized Difference Vegetation Index (NDVI). Changes in vegetation cover have as impact the increasing of the land surface temperature (LST) that is a significant indicative of drought occurrence. This work explored the NDVILST relation through the Vegetation Health Index (VHI) in a tropical environment in Tietê River, State of São Paulo, Brazil, in order to assess changes in vegetation condition in two periods (2000 and 2014). Results showed that stressed areas are coincident with areas presenting high rate of modification in land cover; this areas presented low values of VHI and high values of LST. The worst conditions are verified in 2014, the same period of the most severe drought occurrence that reduced storage capacity in reservoirs in Tietê River.
\end{abstract}

Keywords Drought monitoring $\cdot$ Vegetation health index $\cdot$ Standardized precipitation index $\cdot$ Land surface temperature

\section{Introduction}

Drought is a temporal process related to low relative humidity and reduced precipitation during a season or a year and is recognized as an environmental disaster; droughts have attracted attention around the world, in order to better understand this complex event and to provide options to minimize their damages. Concomitantly to the drought events, water

Enner Alcântara

enner.alcantara@ict.unesp.br

1 Department of Cartography, São Paulo State University, Presidente Prudente, SP, Brazil

2 Department of Environmental Engineering, São Paulo State University, São José dos Campos, São Paulo, Brazil 
scarcity occurrence has often been seen in many parts of the world (Mishra and Singh 2010), as a result of population increase, urban areas growth and expansion of agriculture, energy and industries, that do not accompany the water management policies in the same way.

Drought assessment can be done from remote sensing data, which allow the extraction of biophysical characteristics from land surface. Because droughts naturally involve vegetation changes, satellite data of Earth observations can base the monitoring on vegetation indices (VI) and indices that are dependents only on the rainfall data as the Palmer Drought Severe Index (PDSI) and Standardized Precipitation Index (SPI). Due to its versatility, SPI has been widely used in monitoring droughts in the Brazilian territory, as during Cantareira System reservoirs drought event in São Paulo State in 2014 (Nobre et al. 2016). It was also used in Rio Grande do Sul State with a study of long-term period (1913-2009) of rainfall to monitor the drought that affected the soybean yield (Teixeira et al. 2013) and in Paraná River watershed to monitor two periods of drought, in 2000 and in 2014 (Melo et al. 2016).

The VI involve indices as the Vegetation Supply Water Index (VSWI), Leaf Area Index (LAI), Global Vegetation Index (GVI) from NOAA Advanced Very High Resolution Radiometer (AVHRR) and Normalized Difference Vegetation Index (NDVI) that are indices based on vegetation content, rainfall and soil moisture. These indices are estimated from satellite data, for instance Terra/Moderate Resolution Imaging Spectroradiometer (MODIS), which has been used to monitor droughts in Brazilian northeast in a period of 2 years (2012 and 2014) through the VSWI (Cunha et al. 2015), to analyze agricultural crops in Brazilian territory between 1996 and 1998, via GVI (Liu and Kogan 2002) and the relation between LAI and surface temperature over the years 2003 and 2013 (Anderson et al. 2016).

The NDVI has been widely used over the past decades and became the most common and effective vegetation index to monitor the moisture condition and vegetation state and cover (Bajgain et al. 2015), which are directly related to Land Surface Temperature (LST) conditions. Therefore, NDVI and LST are indices that draw the landscape scenery and can be used to better understand drought events and their impacts via Vegetation Health Index (VHI). Nemani et al. (1993) and Kogan $(1995,2002)$ showed that for drought areas, the NDVI-LST slope should be inversely correlated with VHI reaching low values in temporal analysis. Temporal analysis allows quantifying all the anthropogenic changes in land use and land cover (LULC) that have been widely considered influencing factors in global climate changes (Nagendra et al. 2004).

In Brazil, the economic growth has been followed by significant land use changes so that Tropical forests have become human-modified landscapes (Coe et al. 2011). One example of this is the Atlantic Forest in São Paulo State, which presents high rates of deforestation and fragmentation, with only $7.6 \%$ of its original composition remaining. Most of the Atlantic Forest became a few fragments surrounded by pastures and agricultural areas (Joly et al. 2014). Tropical forests, replaced by agricultural and grazing land areas, substantially shift the rainfalls regime and increase heat fluxes in Earth surface. The modification in precipitation processes impacts reservoirs storage, soil moisture and stream flow; therefore, water availability. Tietê River, for instance, had its storage capacity reduced to around 3\% when São Paulo State received only about one-third to half of its usual amount of rain and presented the most severe drought with 7 months of duration in 2014 (Coelho et al. 2015a, b; NASA 2015), which directly implied in water supply problems (Magalhães 2017). 
The drought in southeast region of Brazil reduced the mean annual supplier of water into the Cantareira system of $44.1 \mathrm{~m}^{3} \mathrm{~s}^{-1}(1930-2013)$ to $11.3 \mathrm{~m}^{3} \mathrm{~s}^{-1}$ in 2014. The Cantareira reservoir system provides water to 8.8 million of habitants in the São Paulo Metropolitan Region (SPMR) and several cities of the state (Nobre et al. 2016). The year of 2014 experienced expressive precipitation deficit besides the two anomalous high-pressure centers over the region that enabled the occurrence of an extreme drought events in terms of impacts and people affected (Coelho et al. 2015a, b; Nobre et al. 2016). In consequence of that, severe policies of water rationing were implanted to adequate the water supply for population that suffered with the availability for human consumption. Others effects of drought were the increasing of forest fires by $150 \%$ from 2013 to 2014 and socioeconomic impacts, mainly tourism activities in rivers and lakes surrounding areas (Marengo and Alves 2016).

Other activities are also affected as agricultural productions of tomatoes, orange and beans that presented increasing of the prices of approximately $30 \%$ in the most in peak of the drought. The sugarcane harvest reduced around 5\% in 2014/2015 in relation to previous years, while production of coffee showed reduction about 15-40\% in São Paulo State. The agribusiness had losses of about US\$ 5 billion in the agricultural sector. The hydropower production, which in Brazil corresponds to $70 \%$ of electricity produced with the majority of them in the southeast region, was reduced with the drier reservoirs, increasing the energy prices around $20-25 \%$ in 2015 . The reduction of water available for human consumption also increased the water bills and creates some inconveniences for basic hygienic of population (Nobre et al. 2016).

Despite the published results showing the southeastern Brazil 2014 drought effects, we cannot find in the literature any mention or classification about the effects on the vegetation health. Therefore, the aim of this work was to classify the southeastern Brazil 2014 drought severity on the vegetation health, through the study of the combined effect of LULC changes and drought events on the vegetation health.

\section{Methodological approach}

\subsection{Study area}

Barra Bonita Hydroelectric Reservoir (BBHR-Fig. 1) (22 36 50.12" S; 48 20 54.57" W), located in the middle of Tietê River Basin, state of São Paulo, is the first of six reservoir built to hydropower generation. The reservoir catchment has shown significant changes due to industrials and agricultural activities since the beginning of the reservoir operation, in 1963 (Tundisi et al. 2008).

The catchment area covers $324.84 \mathrm{~km}^{2}$, with $2.600 \times 106 \mathrm{~m}^{3}$ of nominal volume, used for purposes of fluvial transport (the Tietê-Paraná Waterway), irrigation, tourism, fishing, recreation, urban supply and for providing support to the development of the industrial complex. The predominant vegetation is composed of monoculture of sugarcane (Maia et al. 2008; Dellamano-Oliveira et al. 2008; Prado and Novo 2007), citric crops and cattle breeding according to Integrated System of Water Resources Management of São Paulo State (SigRH).

The reservoir is in the geographic transition between tropical and subtropical climates with a wet season from October to March, and a dry season from March to October (Tundisi et al. 2008), which characterizes a mesothermal classification (CW) based on 

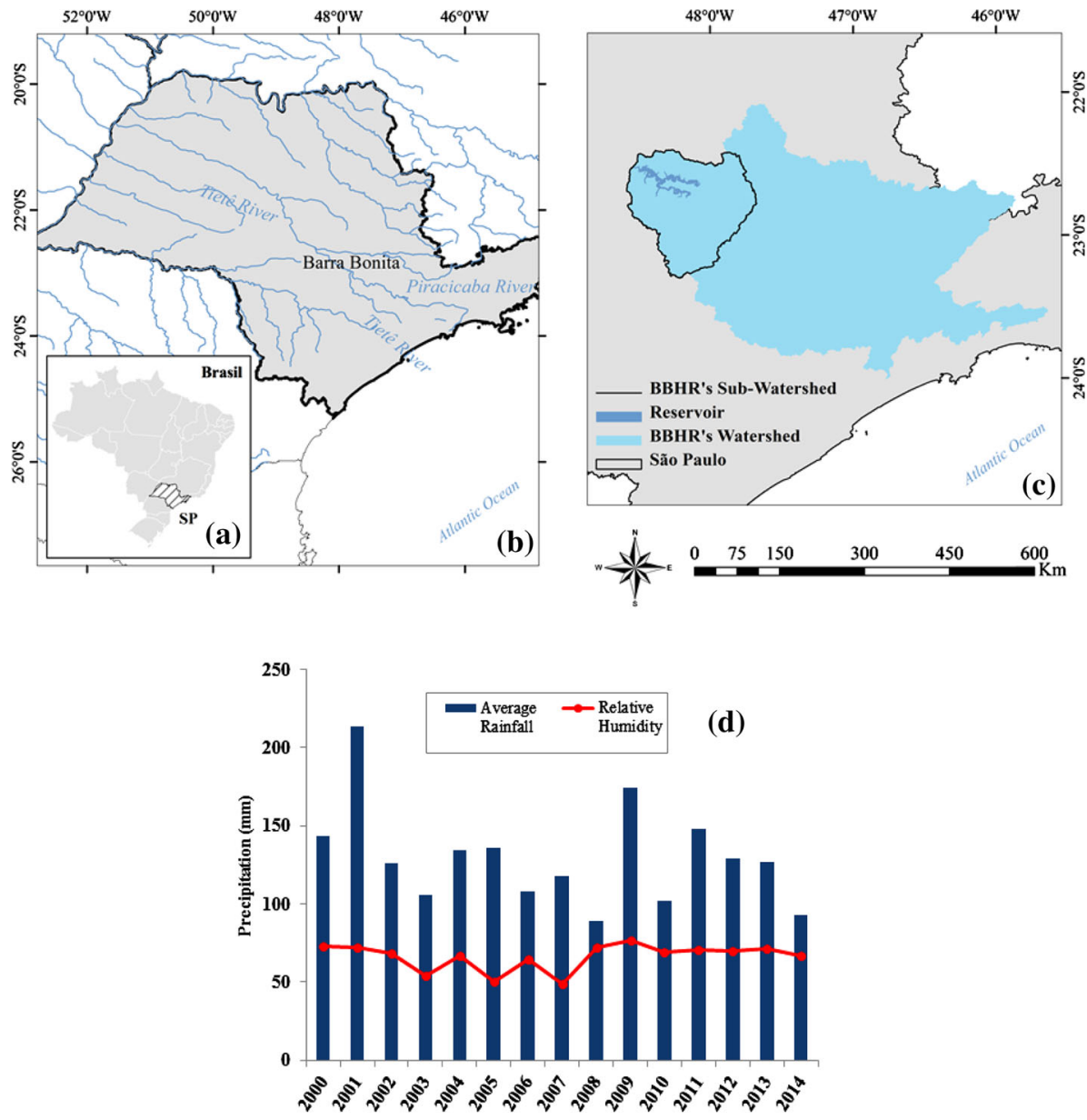

Fig. 1 Study area in Brazilian context (a), localization of Barra Bonita Hydroelectric Reservoir in Tietê River, State of São Paulo (b), Barra Bonita Hydroelectric Reservoir Sub-Watershed within Barra Bonita Hydroelectric Reservoir catchment (c) and the average rainfall and relative humidity data (d) for the period between 2000 and 2014

Köppen classification (Maia et al. 2008). The annual BBHR rainfall is about $130 \mathrm{~mm}$, with temperatures above $30{ }^{\circ} \mathrm{C}$ in the warmest month and temperatures below $20{ }^{\circ} \mathrm{C}$ in the coldest month.

\subsection{Satellite images dataset}

For the time series analysis between 2000 and 2014, the remotely sensed images were acquired on October 22, 2000 by Thematic Mapper sensor onboard Landsat 5 and October 13, 2014 by Operational Land Imager and Thermal InfraRed sensors onboard Landsat 8 (hereafter called TM/L5 and OLI-TIRS/L8, respectively). The satellite images were downloaded from United States Geological Survey (USGS) platform (available at http:// earthexplorer.usgs.gov/). The metadata information from each image is shown in Table 1.

These 2 years were selected in order to present data before and during a drought event. 
Table 1 Summary of the TM/L5 and OLI-TIRS/L8 images used for this study

\begin{tabular}{lllll}
\hline Sensors & Image date & Path/row & Solar azimuth angle & Sun elevation angle \\
\hline TM & $10 / 22 / 2000$ & $220 / 76$ & 74.16 & 57.40 \\
OLI/TIRS & $10 / 13 / 2014$ & $220 / 76$ & 63.99 & 60.06 \\
\hline
\end{tabular}

\subsection{Preprocessing of satellite data}

The geometrical correction was made by register the TM/L5 and OLI/L8 images using at least 12 tie points, well distributed within the entire scene, for correcting all possible geometrical deformations. First-degree polynomial and nearest-neighbor interpolation were used in order to avoid adding new digital numbers in the scene. The Root-MeanSquared Error (RMSE) was lower than 0.5 pixel, which allows comparing the pixels between the bi-temporal images.

The atmospheric correction applied the Fast Line-of-sight Atmospheric Analysis of Hypercubes (FLAASH) method. FLAASH is based on radiative transfer equation that computes the absorption and scattering caused by molecules and particles presented in atmosphere (Adler-Golden et al. 1999). The input data were L5/TM BIL format image, in top of atmosphere radiance $\left(L_{\mathrm{TOA}}\right.$, in $\left.\mathrm{W} \mathrm{m}^{-2} \mu \mathrm{m}^{1} \mathrm{sr}^{1}\right)$. FLAASH result was a L5/TM surface reflectance image $\left(R_{\mathrm{SURF}}\right)$. To reduce the illumination geometry effects, we choose two images acquired on the same month, October (in order to minimize illumination changes derived from sun-earth distance), and applied the Iteratively Reweighted Multivariate Alteration Detection (IR-MAD, Canty et al. 2004) for radiometric normalization. For the IR-MAD application, we used the L5/TM image, in $\mathrm{R}_{\mathrm{SUP}}$ (which was the FLAASH output), and the L8/OLI image, in top of atmosphere reflectance, $\mathrm{R}_{\mathrm{TOA}}$, (obtained as product of the radiometric calibration that uses the metadata file information). Two images in $\mathrm{R}_{\mathrm{SURF}}$, L5/TM and L8/OLI were the outputs were of IR-MAD processing.

\subsection{LULC changes}

The registered and normalized images were used to identify the types of land covers found at BBHR sub-watershed between 2000 and 2014. The classification was made using a nonparametric algorithm, Support Vector Machine (SVM, Vapnik 1995). This algorithm works with the classification error minimization that can be achieved by either fixing the empirical risk in the classification procedure (to obtain a reduced confident interval) or finding an optical hyper plane able to maximize the distance between nearest data that belong to two different classes. The support vector to separate the classes is established based on training data until the machine learn the classes and become capable to categorize the non-training data into the learned classes. This training can add an error (represented by tolerance, C) (Mountrakis et al. 2011) for including some trainer mistakes. The boundaries between the two classes cannot be linear, and then, the algorithm uses a Kernel function to separate them. The Kernel functions can be quadratic, radial (RBF) or polynomial $(p)$. Although the SVM method is not statistical dependent, the algorithm is sensitive to the input parameters and the Kernel function used in the classification procedure.

To achieve an efficient classification in BBHR sub-watershed, several inputs were tested [the pyramid depths $(P)$, the radial basis function parameter $(\gamma)$, the threshold $(L)$, and the 
error tolerance $(C)]$, and the efficiency were evaluated using Kappa Index and Overall Accuracy. After several tests, the most efficient parameters were chosen following the recommendations described in Martins et al. (2016), where SVM was processed using the Radial Base Function. The best SVM results achieved a Kappa of 98\% and overall accuracy of 0.98. The classes of LULC within the BBHR sub-watershed were defined as UNEP/FAO protocol. The classes used in SVM processing were water, bare soil, urban area, grazing land, sugarcane crop, agriculture area (that includes fruit growing such as orange cultivation), forest (dense forest vegetation), vegetation area (non-dense forest vegetation) and residuals (integrating diverse harvested crop areas and eventual forest areas that have been burned).

\subsection{Vegetation health index (VHI)}

The VHI has been applied in a large range of applications. One of these uses is the drought monitoring detection as well as your severity and duration in a period of time (Karnieli et al. 2010). The VHI consists into combine the Vegetation Condition Index (VCI) and the Temperature Condition Index (TCI) that are derived from NDVI and LST, respectively (Kogan 1995, 1997, 2002). The use of NDVI and LST shows significantly relationships to extract information about the water stress on plants, which are related to drought processes. The methodology used to obtain VHI for BBHR sub-watershed consisted of calculating the NDVI and LST for Landsat images taken in 2000 and 2014. To ensure the accuracy of LST, the radiance atmosphere correction was made considering the emissivity of land surface. The emissivity values were derived from NDVI image. Subsequently, the VCI and TCI were calculated and, in combination, they generated the VHI map. Figure 2 summarizes the methodology to obtain the VHI.

Equation (1) shows the relation between VCI and TCI with comparable magnitudes to obtain the VHI values.

$$
\mathrm{VHI}=0.5 \times \mathrm{VCI}+0.5 \times \text { TCI }
$$

The VCI, proposed by Kogan (1995, 1997, 2002), rescaling the NDVI between its maximum $\left(\mathrm{NDVI}_{\max }\right)$ and minimum $\left(\mathrm{NDVI}_{\min }\right)$ values found in the period of interest (Eq. 2). This index highlights the relevant differences in NDVI through the time, minimizing the influence of the vegetation spatial variability between different coverage and climate conditions (Karnieli et al. 2010).

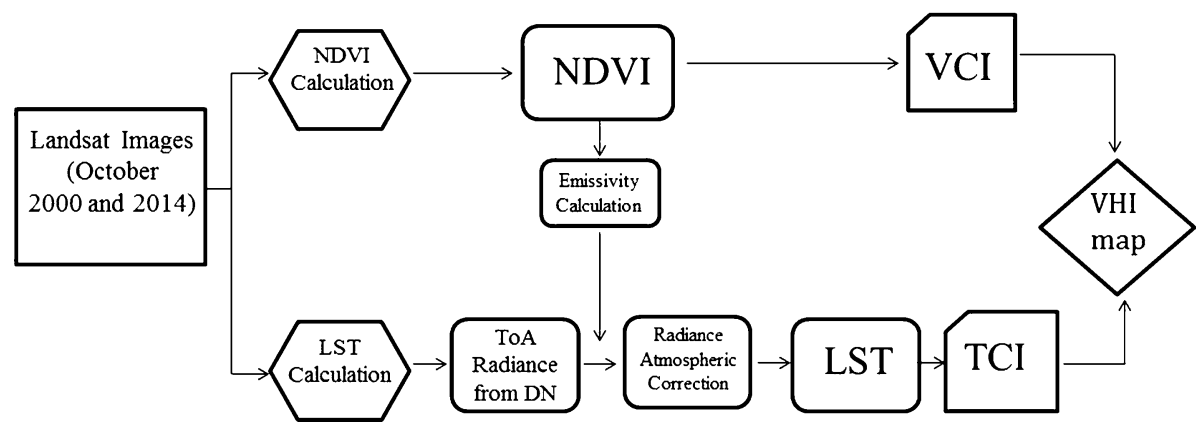

Fig. 2 Schematic flowchart of methodology applied to retrieve NDVI and LST from satellite images to obtain VHI map 


$$
\mathrm{VCI}=\frac{\mathrm{NDVI}^{\prime}-\mathrm{NDVI}_{\min }}{\mathrm{NDVI}_{\max }-\mathrm{NDVI}_{\min }}
$$

where NDVI' is the mean value of NDVI for each year, $\mathrm{NDVI}_{\max }$ and $\mathrm{NDVI}_{\min }$ represent the maximum and minimum value within the scene, respectively. The NDVI is the most frequent index of the vegetation index (VI) used (Valor and Caselles 1996; Sobrino et al. 2004; Karnieli et al. 2010). This is calculated by the ratio between the maximum absorption of radiation in red spectral region (Red) and the maximum reflectance in nearinfrared (NIR) spectral region (3).

$$
\mathrm{NDVI}=\frac{\operatorname{Red}-\mathrm{NIR}}{\operatorname{Red}+\mathrm{NIR}}
$$

An adaption of TCI, index able to estimate the thermal conditions drought the surface, was developed based on LST results (Eq. 4) (Kogan 1995, 2002).

$$
\mathrm{TCI}=\frac{\mathrm{LST}_{\max }-\mathrm{LST}^{\prime}}{\mathrm{LST}_{\max }-\mathrm{LST}_{\min }}
$$

where the $\mathrm{LST}_{\text {max }}, \mathrm{LST}_{\text {min }}$, and $\mathrm{LST}^{\prime}$ are maximum, minimum and medium temperatures (in Celsius), respectively, of the land surface for the 2 years considered in this study.

The VHI map was classified following Kogan (2002) and Kogan et al. (2004) method, with variation ranging from no drought (favorable) to extreme drought (stressed) conditions.

\subsection{Land surface temperature}

In the surface-atmosphere interface studies, LST also has a great representative role in physics processes of energy exchange and water balance at local and global scales ( $\mathrm{Li}$ et al. 2013). Derived from thermal infrared data, LST is useful for land surface conditions as evapotranspiration, vegetation water stress and soil moisture, in addition to providing rich temporal and spatial variability information and can be applied to many purposes (Karnieli et al. 2010). The LST calculation is computed in three steps. Firstly, we convert digital numbers (DN) into radiance at the top of atmosphere for the thermal bands (Eq. 5).

$$
L_{1}=G_{\text {rescale }} \times \mathrm{DN}_{1}+B_{\text {rescale }}
$$

where $G_{\text {rescale }}$ is the rescaling gain factor or multiplicative rescaling factor, DN is the pixel value resident in the specific band and $B_{\text {rescale }}$ is the band-specific rescaling bias factor or additive rescaling factor. The rescaling factors were available in the metadata file from each image.

For a temporal analysis of LST, it is necessary to remove the atmospheric effects in the thermal region. The space-reaching radiance registered at sensor $\left(L_{\lambda}\right)$ is attenuated and enhanced by the atmosphere and must be convert to a surface-leaving radiance for the infrared thermal bands. Barsi et al. (2003) developed an atmospheric correction method, using the radiative transfer model, that requires a specific date, time and location as input besides atmospheric conditions as air temperature $\left({ }^{\circ} \mathrm{C}\right)$, relative humidity $(\%)$ and pressure $(\mathrm{mb})$. The outputs are the estimations of the transmission and the upwelling and downwelling radiances, calculated by a web-based tool (Atmospheric Correction Parameter Calculation) available and provided by NASA. Once these values are known, it is possible to calculate the surface radiance (Eq. 6). 


$$
L_{T}=\frac{L_{\lambda}-L_{\mathrm{u}}+\tau(1-\varepsilon) L_{\mathrm{d}}}{\tau \varepsilon}
$$

where $\tau$ is the transmission, $\varepsilon$ is the emissivity of the surface, $L_{\lambda}$ is the radiance at the top of atmosphere or the space-reaching radiance, $L_{\mathrm{u}}$ is the upwelling or atmospheric path radiance, $L_{\mathrm{d}}$ is the downwelling or sky radiance and $L_{\mathrm{T}}$ is the surface radiance.

To estimate the LST accurately, the emissivity must be estimated; therefore, the NDVI Thresholds (NDVI ${ }^{\mathrm{THM}}$ ) method was used to accomplish this task (Eq. 7). NDVI ${ }^{\mathrm{THM}}$ was developed by Sobrino et al. (2008) and distinguishes soil pixels, vegetation pixels, and mixed pixels (composed by the both covers) from the threshold values of NDVI. Sobrino and Raissouni (2000) proposed values for soil pixels $\left(\mathrm{NDVI}_{\mathrm{s}}=0.2\right)$ and vegetation pixels $\left(\mathrm{NDVI}_{\mathrm{v}}=0.5\right)$ that could be applied in global conditions.

$$
\varepsilon_{\lambda}= \begin{cases}\varepsilon_{s \lambda} & \text { for NDVI }<\mathrm{NDVI}_{\mathrm{S}} \\ \varepsilon_{\lambda}=\varepsilon_{s \lambda}+\left(\varepsilon_{v \lambda}-\varepsilon_{s \lambda}\right) P_{v}+C_{\lambda} & \text { for } \mathrm{NDVI}_{\mathrm{S}} \leq \mathrm{NDVI}_{\mathrm{NDVI}} \\ \varepsilon_{v \lambda} & \text { para NDVI }>\mathrm{NDVI}_{\mathrm{V}}\end{cases}
$$

where $\varepsilon_{\mathrm{s} \lambda}$ corresponds the emissivity value for pixels full of soil, $\varepsilon_{\mathrm{v} \lambda}$ is used to represent emissivity values with vegetation and $C_{\lambda}$ is a roughness factor of the surface (for flats surface the value for $\mathrm{C}$ is equal zero). $P_{\mathrm{V}}$ is the vegetation proportion, and it is calculated from difference ratio between $\mathrm{NDVI}_{\mathrm{S}}$ and $\mathrm{NDVI}_{\mathrm{V}}$.

Aiming to obtain consistent $P \mathrm{v}$ values, it is necessary to set zero for pixels with $\mathrm{NDVI}<\mathrm{NDVI}_{\mathrm{S}}$ (no vegetation) and to set one $\left(P_{\mathrm{V}}=1\right)$ for pixels with $\mathrm{NDVI}>\mathrm{NDVI}_{\mathrm{V}}$ response that means that the pixel is fully of vegetation. Sobrino et al. (2008) reduces the $\varepsilon_{\lambda}=\varepsilon_{\mathrm{s} \lambda}+\left(\varepsilon_{\mathrm{v} \lambda}-\varepsilon_{\mathrm{s} \lambda}\right) \times P_{\mathrm{v}}+C_{\lambda}$ using a typical value for $\varepsilon_{\mathrm{v} \lambda}=0.985$ and $C_{\lambda}=0.005$, considering a mixed area. Simplifying, the final value of $\varepsilon_{\mathrm{v} \lambda}$ is 0.99 . Meanwhile, pixels with NDVI $<\mathrm{NDVI}_{\mathrm{S}}$ means that they are represented by soil and the $\varepsilon_{\mathrm{s} \lambda}$ will be set to values for soil emissivity. For mixed pixels $\left(\mathrm{NDVI}_{\mathrm{S}} \leq \mathrm{NDVI} \leq \mathrm{NDVI}_{\mathrm{V}}\right)$, the $\mathrm{NDVI}^{\mathrm{THM}}$ applied mean values for proportion among vegetation and soil emissivities, since the variations of soil emissivity can be low in cases like the use of low-resolution sensors and it justifies the mean value use.

The NDVI ${ }^{\mathrm{THM}}$ was applied to the TM image with satisfactory results (Root-MeanSquare Error-RMSE-less than 0.01 in relation to in situ measures). The equations used for this sensor are found in Table 4 in Sobrino et al. (2008). The NDVI ${ }^{\mathrm{THM}}$ methodology was also used for the OLI image following the equations of land surface emissivity estimations that were applied according to Yu et al. (2014) that presented RSME of $0.8 \mathrm{~K}$ (kelvins) when provides LST estimations.

Sobrino et al. (2004) evaluated two algorithms to retrieve LST from the Landsat-8, the SC (Single-Channel) and SW (Split-Window) algorithms. The SC algorithm can be applied to any of the TIRS' bands, but the preference is to band 10 (TIRS-1 band) due its spectral position-in a lower atmospheric absorption region. The SW algorithm uses both TIRS bands. Yu et al. (2014) compared LST recovery by SC algorithm, SW algorithm and radiative transfer equation-based method. The last one had the highest accuracy with RSME less than $1 \mathrm{~K}$ when provide surface temperatures. The radiative transfer equation to estimate LST (Eq. 8), proposed by Chander and Markham (2003) to improve calibration procedures for Landsat-5 imagery, is obtained from the Planck's Law equation. 


$$
\mathrm{LST}=\left(\frac{K_{2}}{\ln \left(\frac{K_{1}}{L_{T}}+1\right)}\right)-273,15
$$

where $K_{1}$ and $K_{2}$ are calibration specifics factors of thermal bands (available at metadata file). This equation was applied to thermal band 6 in TM/L5, and band 10 in TIRS/L8 to estimate LST values.

\subsection{Drought assessment}

In order to detect droughts in an easy and statistically relevant way, McKee et al. (1993) developed the Standardized Precipitation Index (SPI). The SPI is able to analyze the dry and wet periods based on probability of precipitation as the only input parameter that turns it easily applicable. The SPI was developed to quantify the precipitation deficit in a period of time, thereby the input should correspond a timescale at the minimum of 3 months. The efficiency of SPI depends on the density of meteorological stations in the region of interest and preferably on a long time scale of data (Cunha et al. 2015).

The SPI was developed for 3-, 6-, 9-, 12-, 24- and 48-month timescales that turn it possible to evaluate different temporal conditions of precipitation and, therefore, allow describing the different impacts related to water supply. The basis of calculation is a longterm precipitation that is fitted to a probability distribution transformed into a normal distribution. The normal distribution contributes to observe the frequency of extreme and severe droughts classifications with consistency. For any location, the timescale of 6-month up to 24-month SPI or more is adequate to verify hydrological drought and applications. McKee et al. (1993) classified the SPI in categories of intensity of the drought as shown in Table 2.

Hayes et al. (1999) used the SPI for monitoring a severe drought in southern Great Plains and in southwestern of USA and showed that the index was able to detect and monitoring the drought. Moreover, it was illustrated how the SPI works to keep up with regional and local progress of the drought along the years. The time identification of emerging drought conditions is also a benefit to appropriate federal and state actions. Du et al. (2013) showed that the SPI at long time scales is more stable to changes in daily precipitation and is more able to highlight periods of annual and temporal series of dry and wet conditions.

Table 2 Categories of drought according to SPI classification

\begin{tabular}{ll}
\hline SPI values & Category \\
\hline$\geq 2.00$ & Extremely wet \\
1.50 to 1.99 & Very wet \\
1.00 to 1.49 & Moderately wet \\
-0.99 to 0.99 & Near normal \\
-1.00 to -1.49 & Moderately dry \\
11.50 to -1.99 & Severely dry \\
$\leq-2.00$ & Extremely dry \\
\hline
\end{tabular}




\section{Results}

\subsection{Drought detection in BB sub-watershed}

The SPI values for Barra Bonita reservoir in Tietê River between 2000 and 2014 were computed from São Carlos gauge station, which is the nearest station with a monthly dataset above 14 years available in the Meteorological Dataset to Teaching and Research (BDMEP) organized by the National Institute of Meteorology (INMET). The data were generated using the 12-month timescale that is able to monitor water crisis as the one occurred in Tietê River in 2014. Figure 3 shows that in 2014 the SPI value in Barra Bonita sub-watershed was -2.35 , and it means an extremely dry situation according the SPI classification proposed in Table 2, registering the most severe event since 2000.

\subsection{Land use and land cover changes}

Table 3 highlights the LULC changes between 2000 and 2014 in percentage; in other words, it reveals the transformations of a class through the years according to changes in land cover and land use. The total of changes that occurred in each class is described in Class Changes lines, meanwhile the values in the diagonal represent the unchanged areas from 2000 to 2014.

The LULC maps (Fig. 4) were generated from the SVM classification of BBHR subwatershed area for 2000 and 2014. In the left side, we can see the map correspondent to 2000 scenery, and in the right side, it is possible to see 2014 scenery.

The changes in northwest (Fig. 4a, b-number 1) and northeast area (Fig. 4a, bnumber 2) are mainly related with the urban areas concentration near the river and the grazing land advance, respectively. Although the grazing land advance, the changes percentage of this class presented low value, $23.49 \%$, among the other classes as shown in Table 3. The vegetation class showed the lowest percentage of transformation $(19.02 \%)$ with the most expressive change of $12.63 \%$ corresponding to agricultural areas (See Fig. $4 a, b$-number 2 ), followed by a rate of $2.64 \%$ corresponding to the sugarcane crops in the streamside areas, and slight changes that were also verified to bare soil, grazing land, urban areas and residual areas.

The changes in sugarcane crop were $44.55 \%$ with transformations of original area into agricultural areas (26.99\%), as observed in Fig. 4a, b (numbers 1 and 3). The second most

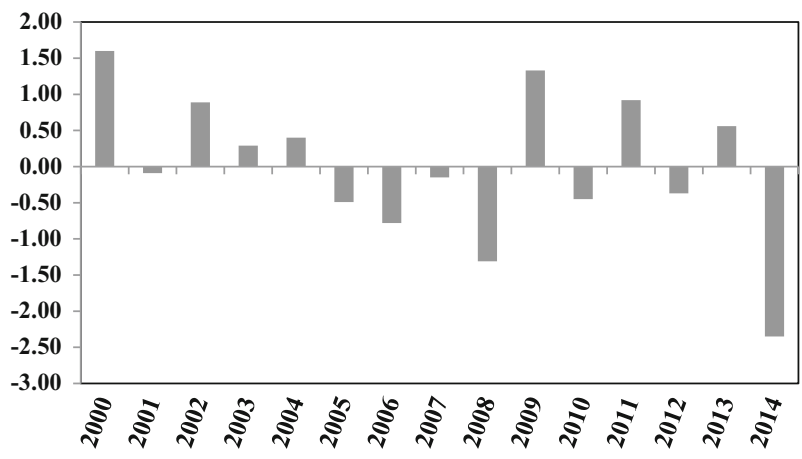

Fig. 3 SPI values for BB watershed from 2000 to 2014 
Table 3 Percentage of LULC changes in BBHR's watershed

\begin{tabular}{|c|c|c|c|c|c|c|c|}
\hline & \multicolumn{7}{|c|}{ Initial state } \\
\hline & Forest & $\begin{array}{l}\text { Bare } \\
\text { soil }\end{array}$ & $\begin{array}{l}\text { Grazing } \\
\text { land }\end{array}$ & $\begin{array}{l}\text { Sugarcane } \\
\text { crop }\end{array}$ & $\begin{array}{l}\text { Agricultural } \\
\text { areas }\end{array}$ & $\begin{array}{l}\text { Vegetation } \\
\text { areas }\end{array}$ & $\begin{array}{l}\text { Residual } \\
\text { areas }\end{array}$ \\
\hline \multicolumn{8}{|l|}{ Final state } \\
\hline Forest & 69.86 & 1.15 & 0 & 0 & 4.79 & 0 & 0.74 \\
\hline Bare soil & 0.43 & 62.43 & 0.43 & 1.52 & 1.74 & 0.93 & 0.42 \\
\hline Grazing land & 1.53 & 8.60 & 76.51 & 0 & 31.69 & 1.53 & 0 \\
\hline $\begin{array}{l}\text { Sugarcane } \\
\text { crop }\end{array}$ & 0.98 & 13.94 & 9.16 & 55.45 & 9.93 & 2.64 & 21.90 \\
\hline $\begin{array}{l}\text { Agricultural } \\
\text { areas }\end{array}$ & 24.25 & 0 & 0 & 26.99 & 45.11 & 12.63 & 0 \\
\hline $\begin{array}{l}\text { Vegetation } \\
\text { areas }\end{array}$ & 2.65 & 2.55 & 4.54 & 0 & 0 & 80.98 & 2.98 \\
\hline $\begin{array}{l}\text { Residual } \\
\text { areas }\end{array}$ & 0.30 & 11.33 & 9.36 & 16.04 & 6.74 & 1.29 & 73.96 \\
\hline Class total & 100 & 100 & 100 & 100 & 100 & 100 & 100 \\
\hline Class changes & 30.14 & 37.57 & 23.49 & 44.55 & 54.89 & 19.02 & 26.04 \\
\hline
\end{tabular}
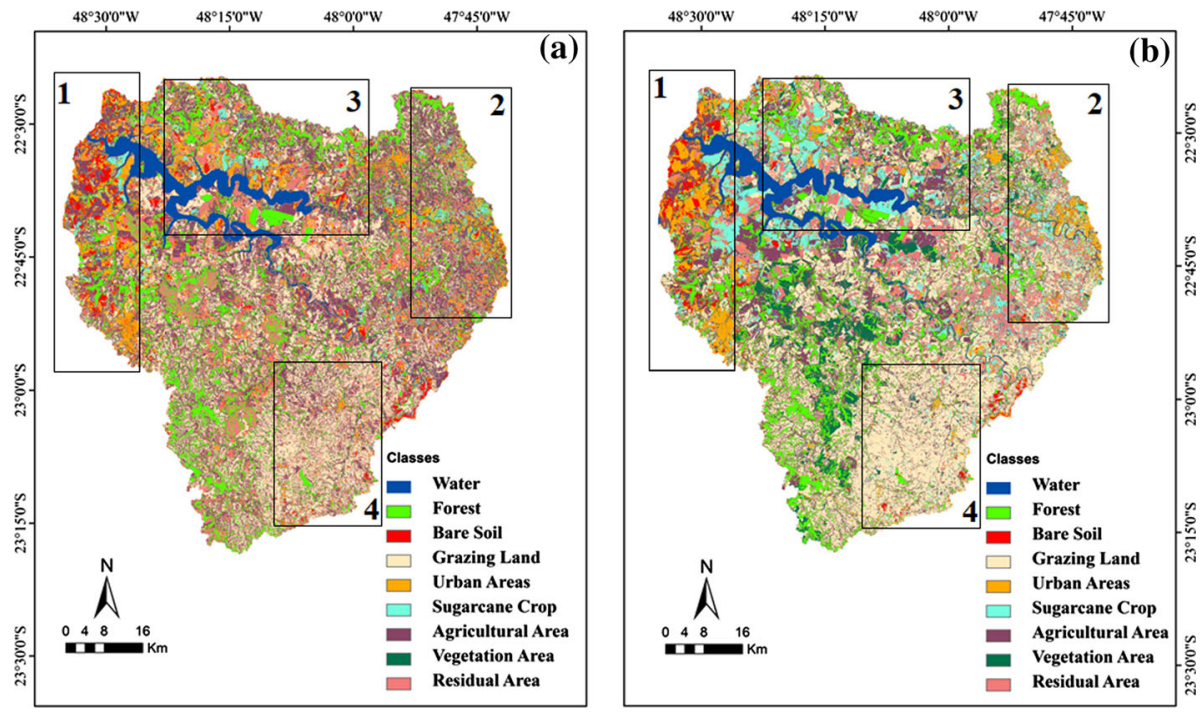

Fig. 4 Land use and land cover of BBHR's sub-watershed in a 2000 and in b 2014

changing was $16.04 \%$ of sugarcane crop that became residual areas, which can be related to the fires used in the pre-harvest. To complete the total of sugarcane crop changes, $1.52 \%$ of the transformations are related to bare soil that can be explained by the continuity of the pre-harvest burning practice and the intensification over the years by 2014. The residual areas, that presented $26.04 \%$ of changes, are mainly linked to sugarcane crop with change 
of $21.90 \%$. In sequence, some residual areas became vegetated area with $2.98 \%$ that can be seen in central region of the BBHR sub-watershed.

The transformations in grazing lands were of $23.49 \%$, replaced mainly in the streamside area (Fig. 4a, b-numbers 2 and 4) by sugarcane crops and residual areas with 9.16 and $9.36 \%$, respectively. The grazing lands showed huge advance in 2014 when compared to 2000, mainly in southeast of BBHR sub-watershed (Fig. 4a, b-number 4) taking the place of $31.69 \%$ of the agricultural areas in 2000 as shown in Table 3. The agricultural areas had the highest value of class changes $(54.89 \%)$ with the higher value related to grazing lands $(31.69 \%)$, followed by sugarcane crops $(9.93 \%)$, due to increasing of production in streamside areas (some parts in numbers 3 and 4 in Fig. 4a, b).

The bare soil were modified to sugarcane crops (13.94\%) and some areas become grazing lands $(8.60 \%)$. Some small areas of bare soil were replaced by forest $(1.15 \%)$, what can be related to revegetation practices as can be seen in the central area of BBHR subwatershed. The forest areas had a significant transformation of $30.14 \%$, for which the highest change was the agricultural areas that took $24.25 \%$ of the total change verified for this class (Fig. 4a, b-numbers 2 and 3). The percentage of $1.53 \%$ of the forest areas became grazing lands in 2014 (Fig. 4a, b-numbers 2) and $0.98 \%$ of the changes is related to sugarcane crops mainly in areas near the reservoir (numbers 1 and 3-Fig. 4a, b).

\subsection{Land surface temperature (LST)}

Temperature has been playing an important role in obtaining useful information about the land surface condition. The surface temperatures found in BBHR sub-watershed ranged between 20.6 and $40.7^{\circ} \mathrm{C}$. The LST calculations allowed the creation of the temperature maps (Fig. 5).

In number 2 of Fig. 5a, b, the increase of the temperature in the bi-temporal analysis is visible. The heat was spread in the north direction near the green areas found in the LULC image of 2000 (Fig. 4a-number 2). Furthermore, in the north area of the BBHR sub-
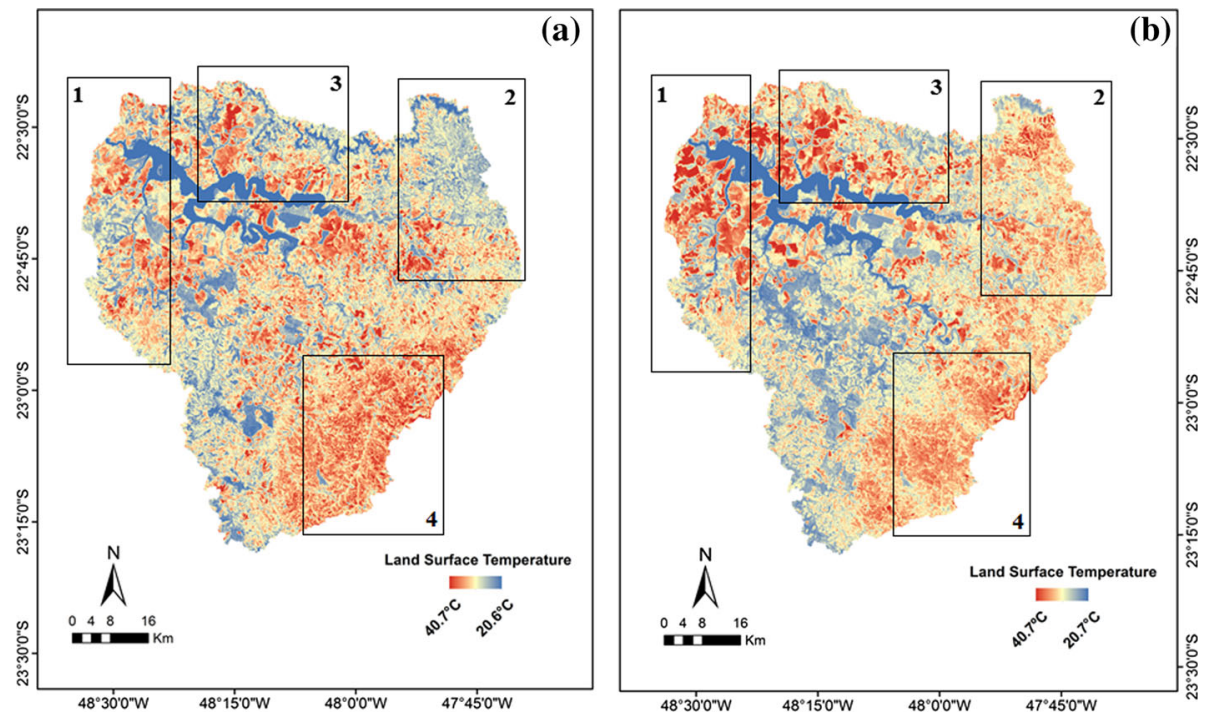

Fig. 5 LST maps of BBHR sub-watershed in a 2000 and in b 2014 
watershed, where there is a forest area, it is possible to see colder temperatures in 2000 than in 2014, when the same area had the percentage of forest reduced by the grazing lands and sugarcane crops advance (Fig. 4a, b-numbers 2 and 3). The central area of BBHR sub-watershed revealed decreasing temperatures over the years that could be explained by the hypothesis of reforestation that should have taken the place of some residual areas that can be seen in Fig. 4a, b. The heat was intensified in areas near the reservoir (numbers 1 and 3-Fig. 5a, b) where there was sugarcane expansion in 2014.

In Fig. 5a, b-number 2, the intensification of temperatures in 2014 compared with 2000 followed the same direction of grazing lands advance on forest areas in the north of BBHR sub-watershed. The transformations in grazing lands verified in Fig. $4 \mathrm{~b}$-number 4 also caused the increasing of the temperatures as shown in Fig. 5a, b-number 4 that were spread along the northeast direction of the sub-watershed. In the total area of the BBHR sub-watershed, the warmest areas in 2014, represented by temperatures near $40.6{ }^{\circ} \mathrm{C}$, outweighed the highest temperatures with $36.14 \%$ in relation to $30.1 \%$ in the fourteen previous years.

\subsection{Vegetation health index (VHI)}

The VHI, as a drought indicator, assumes that the NDVI values should increase with the decrease of LST values, while the VCI and TCI variations are dependent on the local humidity conditions. In this way, when the NDVI values are high it means that VCI values are also high and the same happens for the LST and TCI values. Relied on the inversion proportionality between the LST and NDVI indices, the VHI was computed for BBHR subwatershed. The VCI is able to estimate the moisture condition of the area, whereas the TCI can estimate the thermal conditions. Therefore, when these indexes are joined it is possible to know the climate and vegetation conditions within the study area and relate them with the land use and land cover. Thus, VHI can be used to obtain the moisture availability as well as the coverage resistance by classifying vegetation stress and/or soil water stress (Karnieli et al. 2010). The VHI map was created from VCI and TCI (Fig. 6) and represents how much vegetation is stressed or not into the range from 0 to 100 (Table 4) according to Kogan (2002) and Kogan et al. (2004).

In Fig. 6, four major regions can be highlighted showing the correlation between the existences of vegetation, low temperatures and, consequently, high values of VHI. The number 1 in Fig. 6 highlights some central and western areas of BBHR sub-watershed with favorable values of vegetation condition (around 100) due to the increasing of green areas in 2014 when compared to 2000 (See Fig. 4a, b).

Number 2 represents an area with low NDVI values, with high portions of urban areas and sugarcane crops, revealing high temperatures and low values of VHI. An area without vegetation shows a stressed environment condition and confirms the opposite relation observed in this study between LST and NDVI values that generated the map of VHI. Number 3 in Fig. 6 also reveals a vegetation area, in that case, a forest structure according the maps of LULC (Fig. 4a, b) and it presents a health vegetation condition and low temperature values, even with some changes that occurred over the years. The number 4 in Fig. 6 highlights low values of VHI due to the grazing land advance in this region that reduced NDVI values and increased the temperatures as shown in Fig. 5b-number 4. According to Kogan et al. (2015), the crops productivity and pastures have strong correlation with VHI in countries such as Brazil, Poland, Russia, India and Mongolia and can be used as an indicator of agricultural losses in pre-harvest. 


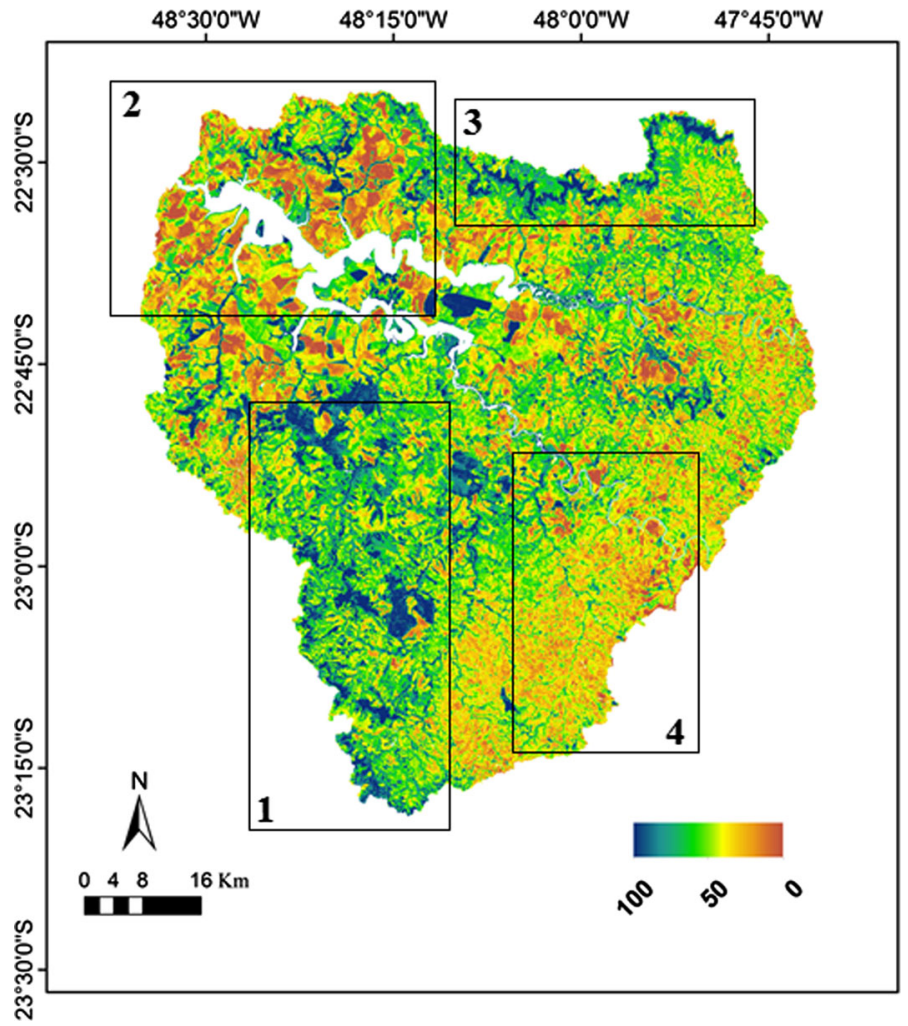

Fig. 6 Vegetation Health Index (VHI) applied to BBHR sub-watershed

Table 4 Classification of VHI values in terms of drought

\begin{tabular}{ll}
\hline VHI values & Drought \\
\hline VHI $\leq 10$ & Extreme drought \\
$10<\mathrm{VHI} \leq 20$ & Severe drought \\
$20<\mathrm{VHI} \leq 30$ & Moderate drought \\
$30<\mathrm{VHI} \leq 40$ & Mild drought \\
$\mathrm{VHI}>40$ & No drought \\
\hline
\end{tabular}

Vegetation areas present a great response of VHI, as some central areas and forest area in north region as shown in Fig. 4-numbers 1 and 2, which means that exists a favorable moisture condition and do not exists stress. In the central region, the residuals replaced by vegetation and agricultural crops through 2000 to 2014 have medium values of VHI (see Fig. 6), showing satisfactory moisture availability and no drought condition. The grazing lands in number 4-Fig. 6 have conditions close to the severe and moderate classification (Table 4). There are soil moisture deficiencies represented by the high LST values (Fig. 3d-number 4) with the increase of grazing land class in 2014. High LST values mean low NDVI values, given that the NDVI value for vegetation pixel is higher than for soil pixel and that the vegetation proportion is considered in the calculation of mixed 
pixels. It means that the reduction of vegetation area through the years caused temperatures increasing in this portion of study area.

The sugarcane areas in northwest of the sub-watershed (Fig. 6-number 2) showed the most severe drought conditions, mainly due to the practices of pre-harvest burning that reduce the soil moisture, increasing the LST and causing stress on vegetation (Fig. 5a, bnumber 1 and 3). The urban areas also demonstrate low values of VHI and extreme drought condition (Fig. 6-number 2) due to the prevalence of compounds that absorb heat in these areas, such as concrete and asphalt, and the absence of green areas, what increase LST values and generate low values of NDVI.

\section{Discussion}

Henderson-Sellers et al. (1993) concentrated some studies about all the impacts that the changes in tropical forests to grazing lands can causes and concluded that the deforestation and reducing in vegetation areas modify the surface roughness that is highly linked to the canopy hydrology and it is the greatest responsible for the changes in surface temperature. The removal of forests reduces the root and leaf density, reducing the water demand and evapotranspiration and warming land surfaces. Water reducing in vegetation characterizes hydrological stress that turns in a drought situation (Panday et al. 2015; Silvério et al. 2015).

In the BBHR sub-watershed, some forest areas in north regions (Fig. 4a, b-numbers 2 and 3) were reduced by the grazing land advance and by the intensification of sugarcane production in areas near the reservoir, increasing the temperatures as can be seen in Fig. 5a, b (numbers 2 and 3). Figure 6 (number 3) shows a favorable condition of the vegetation moisture revealing that the human intervention in this forest area was not so severe. However, in areas apart from the forest fragment the vegetation condition has been affected, which is represented by low values of VHI. Some vegetation areas were replaced by agricultural areas (Fig. 4a-number 2) and some parts of vegetation near the forest areas also were reduced due to urban areas, grazing lands and sugarcane crops advance. The vegetation removal near the forest areas allows alien plants invasion limiting resources for the native plants. They also can alter soil stability; promote erosion; colonize open substrates; and promote or suppress fire. All these processes affect native biodiversity and ecosystem function (Brooks et al. 2004).

The transformations in soil conditions are related to the temperature changes as reveals Fig. $5 b$-number 2 that shows high temperatures in 2014 due to the modifications in vegetation areas in 2000 . High temperatures cause stress condition, and it can be verified in Fig. 6, with low values of VHI in the areas that had the vegetation suppressed. The vegetation removal exposed the soil directly to the solar radiation, increasing the emissivity, and consequently the temperatures. In this same region in 2000 , the temperatures were lower revealing the important role of vegetation in the temperature control. The central area of BBHR sub-watershed presented increasing of vegetation areas in 2014, replacing some residual areas in 2000, which resulted in low temperatures in Fig. 5b and favorable values of VHI in Fig. 6.

In sugarcane scenario, Brazil is the world's leader in ethanol production presenting a recent boom with production of 19 billion of liters in 2017. This production is concentrated in northeast and south central regions. The State of São Paulo accounts for $60 \%$ of production of both sugar and ethanol. Together with that production, many of unsustainable 
environmental and social outcomes factors have been associated. They are atmospheric pollution from fires started to facilitate the harvest, soil degradation, loss of biodiversity, aquatic environments pollution, among others. The sugarcane is continuously harvested in dry season among May and October (Uriarte et al. 2009).

The pre-harvest fires produce carbon monoxide and ozone by burning biomass, increasing its levels in cities where sugarcane is produced. Lara et al. (2005) found that agricultural related factors have an expressive participation in aerosols (black carbon and organic aerosol) in the State of São Paulo, where around $10 \%$ of the total area is used for sugarcane plantations. These aerosols play the major role in the absorption of solar radiation, increasing the surface temperature as can be observed between LULC (specifically sugarcane crops) and LST maps from 2000 and 2014.

Some vegetation and urban areas almost totally became sugarcane crops in 2014 as shown in Fig. 4b (Sect. 3), emphasizing the advanced of these areas. In BBHR subwatershed, the total cultivation of sugarcane increased 4515 hectares between 2003 and 2013 according to surveys made by IBGE (Brazilian Institute of Geography and Statistics) and INPE (Brazilian Institute of Space Research) through Canasat, a research of sugarcane crops monitored by observing Earth satellite images. Figure 7 shows the sugarcane expansion data from Canasat among 2003 and 2013 in BBHR sub-watershed.

The pre-harvest burning practice generates some residuals in the land cover and it was classified as residual areas. These residuals can be related with the pre-harvest burning or recent harvesting of other crops. Therefore, along with the sugarcane crops, we can notice the residual areas advancing in the same direction and presenting high temperatures and deficient moisture conditions (see the numbers 1 and 3 in Fig. 5 b and number 2 in Fig. 6). Some residual areas in the central region of the BBHR sub-watershed turned into vegetation areas revealing supposed reforestation of some old sugarcane areas, improving the vegetation condition of this area, and reducing the temperatures (view Fig. 5b).

The increasing of the sugarcane production and the concentration of the urban areas in the streamside areas caused extremely high temperatures in 2014 (Fig. 4b-numbers 1 and 3). Although the shadow caused by the sugarcane cultivation, the pre-harvest practicals modify the soil dynamics and its water content, increasing the temperature. Dourado-Neto et al. (1999) measured the soil temperature in two types of harvest, one with sugarcane tips and straw from the last harvest and another with the residuals left after the traditional burn practice before the harvest, in a field study in Piracicaba, State of São Paulo, Brazil and it

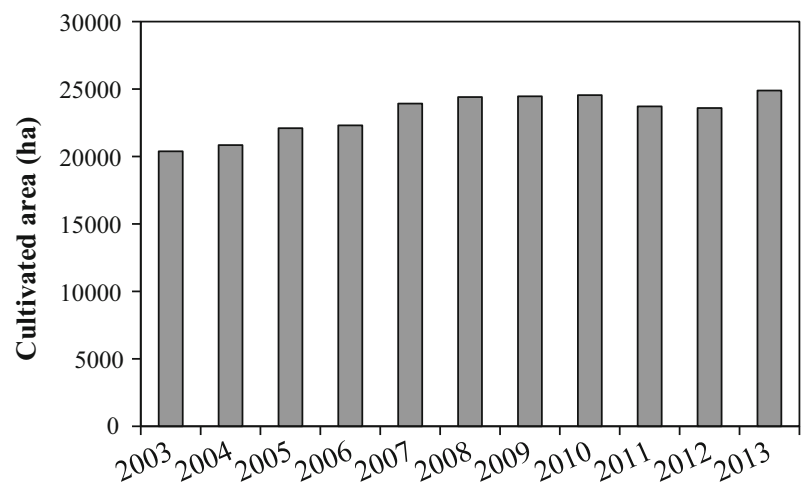

Fig. 7 Total sugarcane cultivation between 2003 and 2013 in BBHR sub-watershed according to CanasatINPE 
was found an increasing of $5.1{ }^{\circ} \mathrm{C}$ in the soil that was burned. The reduction of water followed by increasing of temperatures decreases the VHI values, indicating stress of the land cover as highlight Fig. 6 (number 2) and Fig. 5b-numbers 1 and 3 that reveal the high temperatures found in this region.

The urban areas also showed changes in BBHR sub-watershed with the population density increasing of $7 \%$ according demographic census of 2000 and 2010 raised by IBGE. Population migrated to areas near the reservoir and became more concentrated along the sugarcane crops and in the northeast region of the sub-watershed (Fig. 5a, b-number 2) where were verified the increasing of grazing lands and reducing of vegetation areas. The expansions of urban areas are driven in direction to high temperatures. The modification of the land surface with the great amount of concrete and asphalt in urban areas increases the rate of solar radiation absorption and, consequently, increases the production and energy emission as heat, modifying the exchange of energy and moisture in surface-atmosphere system, increasing the LST trough 2000 and 2014 (Fig. 5a, b-number 2).

Flores et al. (2016) conducted a study about the surface urban heat island from MODIS sensor data in the metropolitan area of São Paulo city that showed strong negative correlations between NDVI and LST in urban areas. The more urbanized areas present lower values of NDVI than rural areas and increasing of around $10{ }^{\circ} \mathrm{C}$ in seasonal amplitudes of LST in relation to rural areas ( $\sim 5 \mathrm{C})$. Areas classified as urban in 2000 already showed high temperatures in Fig. 5a, the same areas had the intensification of temperatures with the increasing of population density and some new urban areas in 2014 also increased the surface temperature as can be seen in Fig. $5 b$.

The expansion of grazing lands over the vegetation areas occurred in direction to the forest areas in north region (Fig. $4 \mathrm{a}, \mathrm{b}$-number 2), turning it into an isolated green area in 2014. Vegetation areas converted into grazing lands can cause lots of damages such as changing hydrological conditions and the water quality in addition to be alarming to the biodiversity of the region (Zedler 2003). The grazing lands modify soil temperature, and these modifications are related to soil respiration. The temperature increases with the increasing of carbon dioxide, accounting for $65 \%$ of carbon dioxide efflux variability (Cao et al. 2004).

In São Paulo state, the grazing lands are used in the most for cattle production that increased 20\% in Brazil between 2000 and 2014 (FAOSTAT 2017). In BBHR sub-watershed the production was around 33,540 heads between 2000 and 2014 according to IBGE Agricultural Census. This grazing lands increasing is easily seen in Fig. 4b-number 4, in the east part of the BBHR sub-watershed with an extensive area and some areas near the expansion of the sugarcane crops. It is possible to notice the expansion of the high temperatures in the same direction that the grazing lands advance and the increasing of temperatures in areas nearby the reservoir, resulting in stressed areas according with the VHI map (Fig. 6).

The areas classified as extreme drought and stressed conditions in BBHR sub-watershed according to the VHI were close to the reservoir that suffered a drought period in 2014 and it could have aggravated a condition already installed due to the changes in land use and cover. In fact, the VHI map highlighted areas that presented expressive changes in LST and LULC maps. Areas with expressive changes in the land use presented high values of VHI such as the vegetation and forest areas that were replaced by grazing land and agricultural activity, mainly sugarcane crops and regions that presented expansion of urban areas. The high values of VHI in this study represented low values of VCI and high values of TCI that reveal the decreasing of NDVI and increasing of LST, respectively. All these changes are responsible for modifying the hydrological dynamic and warming the land surface over the 
years, reducing the VHI values that identified extreme, severe and moderate conditions of drought in areas of the Barra Bonita sub-watershed, confirming the presence of drought event in SPI results.

\section{Conclusions}

The LULC maps revealed relevant changes occurred mainly in relation with some agricultural cultures expansion, such as sugarcane crops and grazing land areas that advanced nearby the reservoir. Some portions of sub-watershed land had increase of vegetation areas, while other vegetation areas were suppressed by the grazing land advance. All these changes represented impacts in the LULC and consequently caused water supply challenges and stressed vegetation condition that can be monitored by the VHI. The VHI is a strong tool of drought detection and allows verify the temporal relation between LST and NDVI for monitoring the major changes in the land use and land cover. For the BBHR subwatershed a wide range, from extreme to no drought conditions, occurred due to extension of this area. The difference of 14 years between our analyses showed many variations in use and land cover and allowed the perception of relating them with the temperature changes. The correlation between LST and NDVI was strongly negative confirming the hypothesis that the areas with low rates of water content in soil and vegetation demonstrated high values of LST and became more stressed areas with low values of VHI. Areas with less modifications that presented high rates of vegetations (high values of NDVI), revealed low values of LST and more health conditions that avoid drought.

Acknowledgments Funding was provided by Fundação de Amparo à Pesquisa do Estado de São Paulo (Grant Nos. 2012/19821-1, 2015/21586-9).

\section{References}

Adler-Golden SM, Matthew MW, Bernstein LS, Levine RY, Berk A, Richtsmeier SC, Acharya PK, Anderson GP, Felde G, Gardner J, Hoke M, Jeong LS, Pukall B, Ratkowski A, Burke HH (1999) Atmospheric correction for shortwave spectral imagery based on MODTRAN4. SPIE Proc Imaging Spectrom 3753:61-69

Anderson MC, Zolin CA, Sentelhas PC, Hain CR, Semmens K, Yilmaz MT, Gao F, Otkin JA, Tetrault R (2016) The Evaporative stress index as an indicator of agricultural drought in Brazil: an assessment based on crop yield impacts. Remote Sens Environ 174:82-99

Bajgain R, Xiao X, Wagle P, Basara J, Zhou Y (2015) Sensitivity analysis of vegetation indices to drought over two tallgrass prairie sites. ISPRS J Photogramm Remote Sens 108:151-160

Barsi JA, Barker JL, Schott JR (2003) An atmospheric correction parameter calculator for a single thermal band earth-sensing instrument. IEEE Int Geosci Remote Sens Symp 5:3014-3016

Brooks ML, D'antonio CM, Richardson DM, Grace JB, Keeley JE, Ditomaso JM, Hobbs RJ, Pellant M, Pyke D (2004) Effects of invasive alien plants on fire regimes. Bioscience 54:677-688

Canty MJ, Nielsen AA, Schmidt M (2004) Automatic radiometric normalization of multitemporal satellite imagery. Remote Sens Environ 91:441-451

Cao G, Tang Y, Mo W, Wang Y, Li Y, Zhao X (2004) Grazing intensity alters soil respiration in an alpine meadow on the Tibetan plateau. Soil Biol Biochem 36:237-243

Chander G, Markham B (2003) Revised landsat-5 TM radiometric calibration procedures and postcalibration dynamic range. IEEE Trans Geosci Remote Sens 41(11):2674-2677

Coe MT, Latrubesse EM, Ferreira ME, Amsler ML (2011) The effects of deforestation and climate variability on the streamflow of the Araguaia River, Brazil. Biogeochemistry 105:119-131

Coelho CAS, Cardoso DHF, Firpo MAF (2015a) Precipitation diagnostics of an exceptionally dry eventin São Paulo, Brazil. Springer, Wien 
Coelho CAS, Oliveira CP, Ambrizzi T, Reboita MS, Carpenedo CB, Campos JLPS, Tomaziello ACN, Pampuch LA, Custódio MS, Dutra LMM, Da Rocha RP, Rehbein A (2015b) The 2014 southeast Brazil austral summer drought: regional scale mechanisms and teleconnections. Clim Dyn 46:3737-3752

Cunha APM, Alvalá RC, Nobre CA, Carvalho MA (2015) Monitoring vegetative drought dynamics in the Brazilian semiarid region. Agric Meteorol 214-215:494-505

Dellamano-Oliveira MJ, Vieira AAH, Rocha O, Colombo V, Sant'Anna CL (2008) Phytoplankton taxonomic composition and temporal changes in a tropical reservoir. Fundam Appl Limnol 171:27-38

Dourado-Neto D, Timm LC, Oliveira JCM, Reichardt K, Bacchi OOS, Tominaga TT, Cássaro FAM (1999) State-space approach for the analysis of soil water content and temperature in a sugarcane crop. Sci Agric 56:1215-1221

Du J, Fang J, Xu W, Shi P (2013) Analysis of dry/wet conditions using the standardized precipitation index and its potential usefulness for drought/flood monitoring in Hunan Province, China. Stoch Environ Res Risk Assess 27:377-387

Flores RJL, Pereira Filho AJ, Karam HA (2016) Estimation of long term low resolution surface urban heat island intensities for tropical cities using MODIS remote sensing data. Urban Clim 17:32-66

Hayes MJ, Svoboda MD, Wilhite DA, Vanyarkho OV (1999) Monitoring the 1996 drought using the standardized precipitation index. Bull Am Meteorol Soc 80:429-438

Henderson-Sellers A, Dickinson RE, Durbidge TB, Kennedy PJ, McGuffie K, Pitman AJ (1993) Tropical deforestation: modeling local to regional scale climate change. J Geophys Res 98:7289-7315

Joly CA, Metzger JP, Tabarelli M (2014) Experiences from the Brazilian Atlantic forest: ecological findings and conservation initiatives. New Phytol 204:459-473

Karnieli A, Agam N, Pinker RT, Anderson M, Imhoff ML, Gutman GG, Panov N, Goldberg A (2010) Use of NDVI and land surface temperature for drought assessment: merits and limitations. J Clim Am Meteorol Soc 24:618-633

Kogan FN (1995) Application of vegetation index and brightness temperature for drought detection. Adv Space Res 15:91-100

Kogan FN (1997) Global drought watch from space. Bull Am Meteorol Soc 78:621-636

Kogan FN (2002) World droughts in the new millennium from AVHRR-based vegetation health indices. Eos Trans Am Geophys Union 83:557-564

Kogan F, Stark R, Gitelson A, Jargalsaikhan L, Dugrajav C, Tsooj S (2004) Derivation of pasture biomass in Mongolia from AVHRR-based vegetation health indices. Int J Remote Sens 14:2889-2896

Kogan F, Guo W, Strashnaia A, Kleshenko A, Chub O, Virchenko O (2015) Modelling and prediction of crop losses from NOAA polar-orbiting operational satellites. Geomat Nat Hazards Risk 7:886-900

Lara LL, Artaxo P, Martinelli LA, Camargo PB, Victoria RL, Ferraz ESB (2005) Properties of aerosols from sugar-cane burning emissions in Southeastern Brazil. Atmos Environ 39:4627-4637

Li Z, Tang B-H, Wu H, Ren H, Yan G, Wan Z, Trigo IF, Sobrino JA (2013) Satellite-derived land surface temperature: current status and perspectives. Remote Sens Environ 131:14-37

Liu WT, Kogan F (2002) Monitoring Brazilian soybean production using NOAA/AVHRR based vegetation condition indices. Int J Remote Sens 23:1161-1179

Magalhães AR (2017) Life and drought in Brazil. In: De Nys E, Engle NL, Magalhaes AR (eds) Drought in Brazil. Proactive management and policy. CRC Press, Boca Raton, FL, p 230

Maia JL, Barbosa AA, Mauad FF, Albertin LL (2008) Uso de Geotecnologias para Análise Espacial da Qualidade da Água no Reservatório de Barra Bonita-SP. Rev Bras de Recur Hídr 2:141-149

Marengo JA, Alves LM (2016) Crise hídrica em São Paulo em 2014: seca e desmatamento. GeouspEspaço e Tempo (Online). 19(3): 485-494. ISSN: 2179-0892

Martins S, Bernardo N, Ogashawara I, Alcantara E (2016) Support vector machine algorithm optimal parameterization for change detection mapping in Funil Hydroelectric Reservoir (Rio de Janeiro State, Brazil). Model Earth Syst Environ 2:138

McKee TB, Doesken NJ, Kleist J (1993) The relationship of drought frequency and duration to time scales. In: Eight Conference on Applied Climatology, pp 179-184

Melo DCD, Scanlon BR, Zhang Z, Wendland E, Yin L (2016) Reservoir storage and hydrological responses to droughts Paraná River basin, south-eastern Brazil. Hydrol Earth Syst Sci 20:4673-4688

Mishra AK, Singh VP (2010) A review of drought concepts. J Hidrol 391:202-216

Mountrakis G, Im J, Ogole C (2011) Support vector machines in remote sensing: a review. ISPRS J Photogramm Remote Sens 66:247-259

Nagendra H, Munroe DK, Southworth J (2004) From pattern to process: landscape fragmentation and the analysis of land use/land cover change. Agric Ecosyst Environ 101:111-115

NASA (2015). Drought shrinking São Paulo Reservoirs. http://earthobservatory.nasa.gov/NaturalHazards/ view.php?id=84564\&eocn=image\&eoci=morenh. Accessed Feb 2017 
Nemani R, Pierce L, Running S, Goward S (1993) Developing satellite-derived estimates of surface moisture status. J Appl Meteorol 32:548-557

Nobre CA, Marengo JA, Seluchi ME, Cuartas LA, Alves LM (2016) Some characteristics and impacts of the drougth and water crisis in Southeaster Brazil during 2014 and 2015. J Water Resour Prot 8:252-262

Panday PK, Coe MT, Macedo MN, Lefebvre P, Castanho ADA (2015) Deforestation offsets water balance changes due to climate variability in the Xingu River in eastern Amazonia. J Hydrol 523:822-829

Prado RB, Novo EMLM (2007) Assessment of the space-time relationships between the UHE Barra Bonita trophic state and its drainage basin pollution potential. Soc Nat 19:5-18

Silvério DV, Brando PM, Macedo MN, Beck PSA, Bustamante M, Coe MT (2015) Agricultural expansion dominates climate changes in southeastern Amazonia: the overlooked non-GHG forcing. Environ Res Lett 10:104015

Sobrino JA, Raissouni N (2000) Toward remote sensing methods for land cover dynamic monitoring: application to Morocco. Int J Remote Sens 21:353-366

Sobrino JA, Jiménez-Muñoz JC, Paolini L (2004) Land surface temperature retrieval from Landsat TM5. Remote Sens Environ 90:434-440

Sobrino JA, Jiménez-Muñoz JC, Sòria G, Romaguera M, Guanter L, Moreno J, Plaza A, Martínez P (2008) Land surface emissivity retrieval from different VNIR and TIR sensors. IEEE Trans Geosci Remote Sens 46(2):316-327

Teixeira CFA, Damé RCF, Bacelar LCS, Da Silva GM, Do Couto RS (2013) Severity of drought using rainfall indices. Rev Ambiente Água 8:203-213

Tundisi JG, Matsumura-Tundisi T, Abe DS (2008) The ecological dynamics of Barra Bonita (Tietê river, SP, Brazil) reservoir: implications for its biodiversity. Braz J Biol 68:1079-1098

Uriarte M, Yackulic CB, Cooper T, Flynn D, Cortes M, Crk T, Cullman G, McGinty M, Sircely J (2009) Expansion of sugarcane production in São Paulo, Brazil: implications for fire occurrence and respiratory health. Agric Ecosyst Environ 132:48-56

Valor E, Caselles V (1996) Mapping land surface emissivity from NDVI: application to European, African, and South America areas. Remote Sens Environ 57:167-184

Vapnik V (1995) The nature of statistical learning theory. Springer, New York

Yu X, Guo X, Wu Z (2014) Land surface temperature retrieval from Landsat 8 TIRS - comparison between radiative transfer equation-based method, split window algorithm and single channel method. Remote Sens 6:9829-9852

Zedler JB (2003) Wetlands at your service: reducing impacts of agriculture at the watershed scale. The ecological society of America. Front Ecol Environ 1:65-72 